\title{
Notas sobre el Diccionario de la lengua española (1917) de José Alemany y Bolufer*
}

\author{
DAVID PRIETO GARCÍA-SECO \\ Universidad Autónoma de Madrid
}

\section{INTRODUCCIÓN}

En torno a 1912 Ramón Sopena encomendaba al «eximio filólogo» Alemany la dirección del Diccionario de la lengua española ${ }^{1}$ obra que saldría de la imprenta cinco años más tarde. Por estas fechas, don José se había ganado la reputación de gran sanscritista, conocedor de la lengua y literatura grecolatinas y excelso arabista. Pero, ¿qué derroteros condujeron al director de dicho diccionario a este reconocimiento?, y lo que es más importante, ¿qué experiencias lexicográficas había cosechado hasta entonces?

Nació José Alemany y Bolufer, el 1 de junio de 1866, en el seno de una familia humilde de agricultores de Cullera (Valencia). ${ }^{2}$ Desde muy temprano mostró poseer una aptitud extraordinaria para el estudio. ${ }^{3}$ En cada una de las distintas etapas de estudiante manifestó ser un alumno brillante, por cuyo rendimiento académico le fueron concedidos en varias ocasiones distintos premios. Durante el servicio militar estudió Filosofía y Letras en la Universidad de Barcelona (1886-1888), donde con posterioridad comenzaría los cursos de doctorado. En marzo de 1890 obtiene finalmente la reválida en Madrid con una tesis titulada Las ideas religiosas, políticas y morales de Jenofonte. ${ }^{4} \mathrm{Al}$ año siguiente (1891) consigue, por oposición, la cátedra de lengua griega en la Universidad de Granada, que ejerció hasta que logra en 1899, también en virtud de oposición, la cátedra de griego en la Universidad Central de Madrid. Hasta entonces sus trabajos consistieron en la traducción de obras del sánscrito (Hitopadeza, 1895; Bhagavad-Gita, 1896). ${ }^{5}$ En 1902, en cambio, publica su Estudio elemental de gramática histó-

\footnotetext{
* Deseo manifestar mi gratitud a D. Pedro Álvarez de Miranda, quien leyó el presente trabajo y con gran amabilidad me ofreció algunas sugerencias que, sin duda, han contribuido a mejorarlo.

${ }^{1}$ En adelante me referiré a él con las siglas $D L E$. Puede consultarse este diccionario en el Nuevo Tesoro Lexicográfico de la Lengua Española (NTLLE) de la Real Academia Española (2001).

${ }^{2}$ Para pergeñar la sumaria biografía de Alemany me sirvo de los datos ofrecidos en la Enciclopedia Espasa $(1909,1930)$, las contestaciones a los dos discursos de ingreso en la Real Academia Española y la Real Academia de la Historia (Alemany 1909 y 1925b, respectivamente), las notas necrológicas de Emilio Cotarelo (1934) y Vicente Castañeda (1934) y, fundamentalmente, el Ensayo bio-bibliográfico de Martínez Camaró (1968). En cuanto al nacimiento de Alemany, Cotarelo (1934: [2]) y Castañeda (1934: 8) indican que se produjo el 1 de julio; sin embargo, Martínez Camaró (1968: 13-14) asegura: «tres partidas de bautismo encontradas por nosotros en el Archivo del Ministerio de Educación Nacional coinciden en atestiguar que el nacimiento tuvo lugar el 1 de junio». Aporta reproducción de una de dichas partidas (1968: 14).

${ }^{3}$ El académico Commelerán afirma que sintió «aspiraciones generosas muy superiores a la humilde condición en que por designio providencial le cupo nacer» (Alemany 1909: 55).

${ }^{4}$ Martínez Camaró (1968: 23-24). El día 23 de ese mes contrae matrimonio con Dolores Selfa y Adam.

${ }^{5}$ Martínez Camaró (1968: 21, 31, 49-52, 56-57). En 1908 dio al público la colección de cuentos Panchatantra. Estas traducciones del sánscrito han venido reeditándose hasta la actualidad.
} 
rica de la lengua castellana, ${ }^{6}$ trabajo que inicia una serie de investigaciones que centran su atención en el español. ${ }^{7}$ E1 14 de marzo de 1909, tras leer el discurso titulado Del orden de las palabras en la lengua indoeuropea, ingresa en la Real Academia Española. ${ }^{8}$ Según Emilio Cotarelo (1934: 1), fue un miembro muy activo en los veinticinco años de vida académica, durante los cuales «logró contar más de mil asistencias». Formó parte, entre otras, de las Comisiones de Gramática, de Autoridades y del Diccionario vulgar; y ejerció los cargos de Vocal adicto a la Junta Administrativa y Censor. En cuanto a los trabajos lexicográficos allí desarrollados, cabe mencionar la participación en la elaboración de las ediciones $14^{\mathrm{a}}, 15^{\mathrm{a}}$ y $16^{\mathrm{a}}$ del diccionario usual ${ }^{9}$ y de la primera del Diccionario manual, 1927 (Zamora Vicente 1999: 206 y 374; Seco 1994). En el año 1925 ingresó en la Real Academia de la Historia (Alemany 1925b). En todo este tiempo, Alemany, además de realizar trabajos de diversa índole -varios de los cuales se publicaron en los boletines de ambas academias- $-{ }^{10}$ seguirá dedicándose a la docencia y a la traducción. El 26 de octubre de 1934 murió en Madrid «víctima de la arteriosclerosis que venía padeciendo desde hacía algunos años» (Martínez Camaró 1968: 35). Póstumamente salió de las prensas, revisada y publicada por su hijo Bernardo Alemany Selfa, su Gramática de la lengua griega (1941).

\section{El Diccionario de la lengua española (1917) De Alemany}

Cuando en 1917 ve la luz el $D L E$, Alemany llevaba ocho años como miembro de la Academia. La pertenencia a dicha institución, además de haberle procurado en gran medida la dirección del vocabulario proyectado por Ramón Sopena, ${ }^{11}$ le obligaba a justificar la elaboración de un trabajo lexicográfico que no solo se beneficiaba del diccionario académico, sino que competía con él. ${ }^{12}$ La justificación quedaba expuesta en el prólogo, basada fundamental-

${ }^{6}$ Al final del trabajo puede consultarse el Apéndice I, en el que aparecen cronológicamente las publicaciones de Alemany y Bolufer citadas en este estudio. Ante todo, encontrará el lector trabajos de índole lingüística y, especialmente, los vinculados con el léxico. Para una relación bibliográfica más amplia puede recurrirse a Martínez Camaró (1968).

7 1915b-1916a, 1916b-1917a, 1917c y 1919, 1920, 1925a, 1926 y 1930.

8 «Detrás de Liniers, accede a la silla S un universitario dedicado a las lenguas clásicas: José Alemany Bolufer» (Zamora Vicente 1999: 206).

${ }^{9}$ Cotarelo (1934: [2]) señala que fue «corrector casi único de las ediciones 13 y 14». Sin embargo, no parece que participara en la de 1899, no solo porque en esta época-como hemos visto- se hallaba atareado con otros muchos menesteres, sino que su nombre (y esto me parece más determinante) no figura en los preliminares de dicha edición.

10 1915a, 1927, 1928, 1929a, 1929b, 1931, 1932 y 1933. Véanse los trabajos vinculados a la Real Academia de la Historia en Martínez Camaró (1968).

${ }^{11}$ La portada del $D L E$, al igual que los múltiples y variados vástagos a que dio lugar tal trabajo (incluso cuando ya había fallecido don José, vid. una relación, no exhaustiva, de los mismos en Martínez Camaró 1968: 83-84; $c f$. Alvar Ezquerra 2002: 367-371), ostenta la dirección del académico como garante de calidad; al tiempo que supone un evidente reclamo comercial.

12 Desconozco cuál sería la actitud de la Academia ante tales iniciativas; máxime cuando estas constituían para la Corporación -como digo- un competidor del repertorio «oficial». La única alusión que conozco sobre este punto (y he de decir que no es nada clara) es la expuesta, a la muerte de Alemany, en la nota necrológica de Emilio Cotarelo (1934: [6]). En ella se alude, una vez citada «la última obra de alguna importancia [se refiere a la contestación al discurso de ingreso de Luis Fullana Mira]» (vid. Martínez Camaró 1968: 114-116), a «los dos Diccionarios que hizo para la casa Sopena de Barcelona [probablemente aluda, además de al $D L E$, a la edición abreviada del mis- 
mente en tres aspectos. Primeramente, se afirmaba que cualquier perfeccionamiento y enriquecimiento del léxico académico, «siempre que se obre con la discreción y el tino necesarios, será labor meritoria». Esto podía conseguirse -continúa- porque «la Academia tiende a hacer de su Diccionario una obra de selección» que «no puede dar cabida en su léxico más que a las voces cuyo uso han sancionado los buenos hablistas»; de manera que, así, deja sin registrar «un cuantioso caudal que usa el pueblo y con él los literatos». Como último punto sostiene que el repertorio académico acusa una importante carencia de «miles de voces técnicas». Manifestadas las anteriores razones, dice que su propósito no ha sido otro que elaborar un diccionario que, siendo complemento del académico, ${ }^{13}$ logre ser «un registro, lo más completo posible, de la lengua hablada». Pues bien, veamos de qué modo trató de conseguir tan ambicioso proyecto. Desde la portada se nos dice:

Esta obra consta de 120.000 artículos, y contiene todas las voces de la 14. ${ }^{\mathrm{a}}$ edición del Diccionario de la Academia y unas 40.000 más, sancionadas por el uso y por la autoridad de buenos hablistas, entre las que se cuentan más de 25.000 americanismos y numerosos vocablos técnicos.

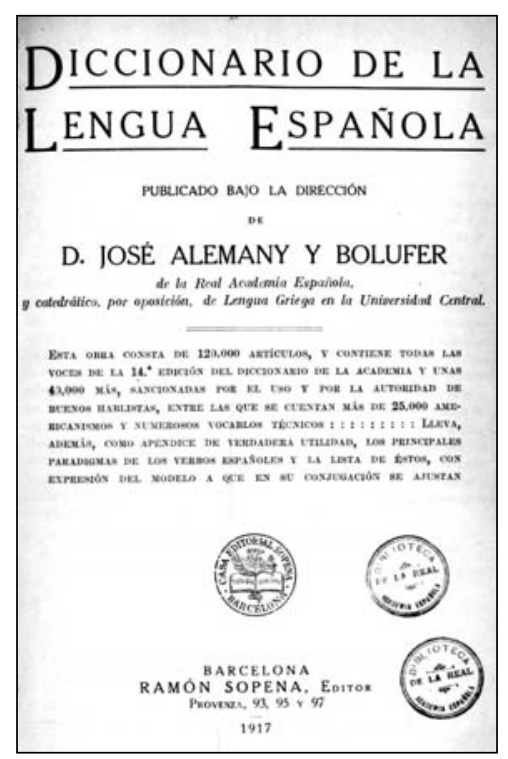

De acuerdo con estos cómputos, en primer lugar, se desprende que el diccionario académico, en tal edición, debería de tener alrededor de 80000 artículos, lo cual significa que el $D L E$ lo supera en un 50\%. Por otro lado, se da la cifra de 25000 americanismos, es decir, un

mo (Alemany 1923; vid. Martínez Camaró 1968: 83), o acaso a la versión enciclopédica, también procedente de idéntico padre (Alemany, 1921)] y que, aunque quizás abreviaron su vida por el enorme y largo trabajo que le causaron, también le dieron la áurea medianía de que habla el poeta [Leandro Fernández de Moratín (?)] con que pudo rodear a su familia» (Cotarelo 1934: [6]). Téngase en cuenta que Alemany llegó a tener nueve hijos, aparte de los cinco malogrados (Martínez Camaró 1968: 25).

${ }^{13}$ Afirma: «Junto al [diccionario] de la Academia, al cual siempre hay que acudir en primer término, como madre que es de todos, deben existir otros que abriendo sus páginas a las muchas voces, ya vulgares, ya técnicas, que forman parte integrante del idioma, pero que la Academia deliberadamente no ha incluido todavía en el suyo, sirvan de verdadero complemento a este»; y, poco después, insiste en que la obra realizada ha querido «ofrecer a quienquiera que haya de consultarla verdaderas garantías respecto de las dicciones que no figuran en el léxico oficial» (Alemany 1917b: [V]-VI). 
$20.83 \%$ del total, o lo que es igual, una quinta parte del mismo. ${ }^{14} \mathrm{Y}$ por último, aunque no se mencione con igual precisión, se dice que se registran «numerosas voces técnicas». ${ }^{15}$ Aún más halagüeños son los resultados que se desprenden de la comparación entre el número de entradas registradas en determinadas letras en el diccionario de Alemany y las correspondientes en el académico. En el cuadro siguiente podemos observar en cursiva, en la columna segunda y tercera, ${ }^{16}$ el número total de entradas contenido en cada una de las letras elegidas. La última columna muestra la diferencia existente entre ambos totales.

\begin{tabular}{|l|l|l|l|}
\hline LETRA & Academia $(1914)$ & Alemany $(1917 \mathrm{~b})$ & Diferencia \\
\hline $\mathrm{J}$ & $593+3=596$ & $1239+32=1271$ & 675 \\
\hline $\mathrm{K}$ & 22 & $228+4=232$ & 210 \\
\hline$\tilde{\mathrm{N}}$ & 19 & 82 & 63 \\
\hline $\mathrm{O}$ & $979+8=987$ & $2164+15=2179$ & 1192 \\
\hline $\mathrm{Q}$ & 288 & $730+3=733$ & 445 \\
\hline $\mathrm{V}$ & $1451+2=1453$ & $2159+10=2169$ & 716 \\
\hline $\mathrm{Y}$ & 103 & $300+6=306$ & 203 \\
\hline $\mathrm{Z}$ & $468+2=470$ & $770+14=784$ & 314 \\
\hline TOTAL & 3938 & 7756 & 3818 \\
\hline
\end{tabular}

Esta comparación nos da como resultado que el $D L E$, en tales letras y teniendo en cuenta solo el número de artículos (no el de acepciones), aumenta el caudal léxico en un $96.95 \%$ con respecto al diccionario académico. Es probable (y esperable de acuerdo con las cifras de la portada a que antes me he referido) que la diferencia entre ambos repertorios no sea tan grande, pero lo cierto es que, atendiendo a aquellas cifras (las de la portada) o a las desprendidas del cotejo de estas letras, estamos ante una de las características de este diccionario: el gigantismo. En este sentido el $D L E$ se hace heredero de una de las prácticas (y técnicas comerciales) de la lexicografía del siglo XIX, consistente en anunciar generalmente desde las portadas que el léxico inventariado supera ampliamente al académico. Ahora bien, ¿de qué modo se logra este aumento? En el prólogo del $D L E$ podemos observar cuál es la concepción de Alemany sobre la labor del lexicógrafo; su trabajo -asegura-

no es inventar, sino recoger, fijar y dar unidad a lo que ya existe: su oficio, más que de autor, es de juez escrutador que, examinando con atención y detenimiento los materiales legados por los que le han precedido, y sin perder de vista el estado actual de la lengua, sepa dar el visto bueno a aquello que lo merece y echar a un lado lo inútil y embarazoso (Alemany 1917b: VI).

\footnotetext{
${ }^{14}$ Más adelante, cuando me refiera a la inclusión de voces marcadas diatópicamente, veremos que no es oro todo lo que reluce.

${ }^{15} \mathrm{~A}$ ellas también me referiré más adelante. En cuanto a los aspectos externos, ha de indicarse que el $D L E$ es un volumen de 1747 páginas, compuesto por el cuerpo del diccionario (hasta la p. 1 692, distribuido el texto en tres columnas), un suplemento de 15 pp. (de la 1693 a la 1 708), un apéndice con la «conjugación de los verbos españoles» (1 709 a 1746 ) y, finalmente, una página de «correcciones y erratas» (p. 1747$)$. Por su parte, el diccionario académico tiene un total de 1073 páginas (hasta la p. 1069 el cuerpo central, y de la 1071 a la 1073 de suplemento). Por lo tanto, el $D L E$, en relación con el repertorio de la Academia, tiene un $62.81 \%$ más de páginas, aunque conviene subrayar, en favor de este último, que el formato del diccionario académico es mayor.

${ }^{16}$ Cuando aparecen en una casilla dos cifras sumadas antes del total (en cursiva), la primera corresponde al número de artículos existentes en el cuerpo del diccionario y la segunda al suplemento.
} 
Aunque parece inferirse de estas palabras cierto normativismo a la hora de registrar las voces («juez escrutador», «dar el visto bueno»), vamos a ver que, más bien, la labor principal es el allegamiento de materiales lexicográficos anteriores, metodología que, si bien dista mucho de la empleada para los trabajos actuales, ha venido siendo una práctica habitual incluso desde el propio Diccionario de autoridades (1726-1739). ${ }^{17}$

En primer lugar, Alemany toma como base casi en su totalidad la macroestructura y microestructura de la $14^{\mathrm{a}}$ edición del diccionario académico. Sin embargo, decide suprimir los refranes; determinación que tomará la misma Academia en 1970. ${ }^{18}$ La asunción del modelo académico en ocasiones (acaso demasiadas) se lleva a cabo de manera acrítica. Para estudiar las peculiaridades del $D L E$ voy a servirme (aunque no únicamente) de la página que comprende de la voz cipipa a circulatorio. ${ }^{19}$ Uno de los aspectos que pudiera haberse superado lo encontramos en la definición de los gentilicios. En el corpus seleccionado la voz circasiano posee dos acepciones, una reservada para las personas: «natural de Circasia» (con la marca gramatical «ú. t. c. s.») y otra básicamente referida a las cosas: «perteneciente o relativo a dicha región de la Rusia europea». Se observa claramente que la segunda acepción depende de la primera. Esta falta de autonomía, que se produce del paso de la $11^{\mathrm{a}}$ a la $12^{\mathrm{a}}$ edición académica (y en la que no me puedo detener), llega a la edición de que se sirve Alemany y, sin reparar en lo inadecuado del segundo enunciado definitorio, se copia tal cual. ${ }^{20}$ Pese a que metodológicamente no resulta idóneo ofrecer definiciones dependientes (normalmente de la anterior), el ejemplo comentado, no obstante, no supone ningún tipo de problema siempre que se lea una acepción detrás de otra, de manera que la deíxis adquiera sentido. El verdadero inconveniente de estos enunciados «dependientes» se manifiesta cuando se realiza alguna modificación, ya sea por adición o por supresión de acepciones. En el artículo de la palabra circo, el $D L E$, probablemente por error de copia, no registra la tercera acepción que traía el diccionario académico, cual es: «conjunto de asientos puestos en cierto orden para los que van de oficio o convidados a asistir a alguna función». Esta ausencia habría pasado inadvertida si no fuera por la huella existente en lo que he llamado acepción dependiente. Esta huella la hallamos en la tercera acepción (cuarta en el académico), que dice así: «conjunto de personas que ocupan estos asientos». El consultante, ante tal enunciado, trata de buscar en la acepción anterior de qué asientos se trata, pero no los encuentra.

Aunque -como digo-en general se copió la edición académica de 1914, existen, no obstante, algunos cambios en relación a esta. Uno de ellos consistió en la reducción de acepciones (cf. cipo, $1^{\mathrm{a}}$ acep.), y sobre todo de las enciclopédicas (circo, $1^{\mathrm{a}}$ acep. ${ }^{21}$ o caballo). El

${ }^{17}$ A lo largo de este trabajo voy a centrarme en la recepción de las distintas fuentes secundarias o lexicográficas (y quizá las únicas) en el $D L E$. Aunque en el prólogo parece aludirse a fuentes primarias al afirmarse que «solo se han admitido [las voces] cuando de la compulsa de textos y autores ha resultado evidente su uso, o, en otro caso, cuando figuran en más de un Diccionario de suficiente autoridad» (Alemany 1917b: VI), lo cierto es que no he logrado encontrar ninguna prueba clara de la utilización de aquel tipo de fuentes.

${ }^{18}$ En el Preámbulo de dicha edición (la $19^{\mathrm{a}}$ ) se alude a «la decisión adoptada por la Academia de eliminar del DiCCIONARIO los miles de refranes que contenía» (Academia 1970: VIII).

${ }^{19}$ No tengo en cuenta el artículo círculo, último de dicha página, pero que continúa en la siguiente. Véase el Apéndice II.

${ }^{20}$ En este caso existe una pequeña modificación entre el $D L E$ y el diccionario académico, pero esta es insignificante. Se cambia «perteneciente a esta» por «perteneciente o relativo a dicha».

${ }^{21}$ Nótese, además, que se separa de la definición la información de contexto o pragmática mediante su anteposición y separación con una coma («Entre los romanos, lugar destinado [...]»). 
sistema de remisiones también fue objeto de una de las innovaciones -a mi juicio- más positivas que introduce Alemany, si bien, lamentablemente, no es lo sistemática que sería de desear. La Academia empleaba la letra negrita en estos casos y, en ocasiones, indicaba mediante una especificación numérica a qué acepción se remitía. Alemany, además de este sistema, ${ }^{22}$ hace uso de otro más claro que consiste en señalar después de la remisión a qué acepción se refiere mediante la copia, casi siempre parcial, de esta ( $c f$. ciquitroque: «Pisto, en la acep. de fritada de pimientos, tomates, etc.»; o circo, $4^{\text {a }}$ acep.: «Cerco, en la acep. de figura supersticiosa, etc.»). Este sistema también se adoptará en el futuro para el diccionario académico. ${ }^{23}$

Pero pasemos a ver de qué modo se consiguió llegar a las cifras que más arriba he mencionado. Después del prólogo escrito por Alemany, figura una «lista de las obras consultadas para la redacción de este diccionario» (Alemany 1917b: VII-VIII). En ella aparecen consignadas alrededor de ochenta obras de muy distinta naturaleza. Predominan los diccionarios monolingües de español y los repertorios de voces técnicas y voces marcadas diatópicamente, pero también se citan diccionarios monolingües extranjeros, bilingües con lengua española, bilingües sin español; incluso se mencionan diccionarios etimológicos, diccionarios enciclopédicos españoles y extranjeros, trilingües, etc. Como puede verse, se trata de un corpus de obras sumamente heterogéneo. Estas obras -evidentemente- no darían el mismo servicio al DLE. Alemany aseguraba en el prólogo que se había valido de todas y cada una de las obras, pero que lo hizo «en mayor o menor grado en orden a su mérito» (1917b: VI). No sabemos si fue por su mérito, pero lo que es cierto es que se volcaron masivamente las obras de tecnicismos y voces pertenecientes a un territorio determinado del ámbito hispánico, regionalismos, $\mathrm{y}$, ante todo, americanismos. Veamos qué ocurre con los primeros.

El fragmento del $D L E$ que estamos analizando presenta, por un lado, 71 entradas frente a 24 del académico, y por otro, 81 acepciones frente a $38 .{ }^{24}$ Ahora bien, si reparamos en cada una de las entradas, se cae en la cuenta de varios aspectos. En primer lugar, nos encontramos con que más de la mitad de las acepciones (un total de 48) aparecen marcadas, bien diatópicamente, bien con marca técnica de diversos ámbitos. ${ }^{25}$ Aunque estos cómputos se refieran a la página seleccionada como botón de muestra, basta con hojear el $D L E$ para advertir que la abundante recepción de voces marcadas es la tónica general. No en balde, como he señalado más arriba, se

${ }^{22}$ Que ha acarreado en alguna ocasión errores de remisión. Estos se han producido cuando, ante la adición o supresión de alguna acepción en determinado artículo (con la consecuente alteración del orden), no se ha modificado en la remisión el número de la acepción a que se enviaba.

${ }^{23}$ La Academia suprimirá las referencias numéricas en la $19^{\mathrm{a}}$ ed. «dando al lector la sola definición directa, entera o reducida, de la acepción [a que antes se remitía]» (Academia 1970: [VII]). Asimismo, existen otras modificaciones de menor calado: transcripción de las etimologías griegas y árabes con el alfabeto latino (vid. ciprés, circón); marcación técnica inadecuada de acepciones ( $1^{\mathrm{a}}$ de ciprés); modificación de enunciados definidores sin alteración semántica relevante ( $c f$. ciquiricata, circense, circuito aceps. $1^{\mathrm{a}}$ y $3^{\mathrm{a}}$ ); modificación de enunciados definidores con alteración semántica relevante $\left(c f .5^{\mathrm{a}}\right.$ acep. de circular $^{[1]}, 4^{\mathrm{a}}$ acep. de circular $\left.^{[2]}\right)$. Incluso existe alguna errata, como ocurre en la adscripción de la voz cipridopatía a la categoría adjetivo (se define como «nombre genérico de las enfermedades venéreas»)).

${ }^{24}$ En estos artículos encontramos en el DLE 19 remisiones, mientras que el diccionario académico presenta 7. Coinciden tan solo en el número de unidades pluriverbales (ciprés de Levante, s. v. ciprés, y circulación de la sangre, s.v. circulación).

${ }^{25}$ Pertenecientes a la Zoología cuento hasta 14 acepciones, 6 de la Botánica, 2 de la Patología, 2 de la Mineralogía, 2 de la Química y 1 de cada uno de los siguientes ámbitos del saber o actividades humanas: Geología, Arqueología, Minería, Astrología, Física, Fisiología y Geometría. 
empleó un número considerable de diccionarios técnicos. Alemany decía en el prólogo: «existen asimismo miles de voces técnicas que la Academia no incluye tampoco en su Léxico y cuya explicación sólo halla, aquel que necesite averiguarla, en los Diccionarios técnicos de Medicina, Historia Natural, Artes e Industrias, etc., y otras obras especiales» (Alemany 1917b: v). Este hecho, al margen de la conveniencia o inconveniencia de incluir en un diccionario general todo tipo de tecnicismo, puede conllevar algún que otro problema en el sistema interno del mismo vocabulario. Es el caso de la voz ciprina, voz técnica de la Mineralogía definida del siguiente modo: «variedad cuprífera de hidrocrasa». Uno de los requisitos deseables de un diccionario general es el cumplimiento del principio de autonomía, o dicho de otro modo, todas las palabras que se empleen para definir deben figurar en la macroestructura, de modo que si el consultante, tras leer el enunciado definitorio, desconoce algún término allí utilizado, pueda resolver su duda con el propio diccionario. Pues bien, en vano se buscará la voz hidrocrasa de la definición anterior, pues no se registra en el $D L E .{ }^{26}$ Este es uno de los múltiples problemas que conlleva la copia indiscriminada de diccionarios técnicos sin el debido celo.

En cuanto a la recepción de voces marcadas diatópicamente, cabe señalar que el $D L E$ fue pródigo en su recogida. En este aspecto destaca el papel de la obras de Miguel Toro y Gisbert, de 1912, Americanismos y el probablemente de todos más conocido Pequeño Larousse Ilustrado, diccionario que «abría la puerta al americanismo» (Álvarez de Miranda 2004: 224). Ambas obras fueron abundantemente despojadas por Alemany (1917b: VIII). Algo más de manga ancha, sin embargo, tuvo con otro tipo de voces que quiso diferenciar de los americanismos. Me refiero a voces con marca de araucanas (mencue, miñumiñe, pichapicha, quechán, quechatún), guaraníes (parachí, urubutí, urucureá), malayas (saplugán), quechuas (ulurunco), etc. La recogida de estos términos, ciertamente copiosa, es quizá uno de los talones de Aquiles del diccionario, ya que su pertenencia al español es más que dudosa.

Es manifiesto, por tanto, que Alemany se valió en distinta medida de una gran variedad de repertorios léxicos. Parece ser que al comienzo de la elaboración del diccionario se barajó la posibilidad de citar la autoridad lexicográfica de donde se obtuviera la voz o la acepción en cuestión, pero finalmente esta idea fue rechazada (Alemany 1917b: VI). Sin embargo, el criterio general de callar la fuente no siempre se cumplió, puesto que en algunos artículos quedaba expresa cuál había sido la obra copiada. Es el caso de la voz cipitillo, en la que leemos: «en la República de Salvador, según Toro y Gisbert, duendecillo que come ceniza». ${ }^{27}$ Del mismo modo, se cita a otros lexicógrafos como González de la Rosa en las voces huamino, huanúchil, huasicama; ${ }^{28}$ Rodríguez Navas en huahates y micotreto, ${ }^{29}$ e incluso se alude, cuando el diccionario ha sido fruto de varios autores, al título de la obra, como ocurre con el Diccionario enciclopédico hispano-americano (en adelante $D E H A$ ), citado en los términos diantinias, faidas, huachiparis, huamanripa, magú, mahori, pachana, pachocha, reneta, etc. Precisamente esta última obra puede servir para mostrar la entrada de otro tipo de voces en el $D L E$.

\footnotetext{
${ }^{26}$ Esto mismo ocurre, entre otras muchas voces técnicas, con el término sulfoantimoniuro, empleado para definir la palabra semseyita. Se registran, en cambio, otros tecnicismos de extraordinaria rareza como sulfoantimónico o sulfoantimonioso.

${ }^{27}$ Otras alusiones a este mismo autor las encontramos en las voces caita, choroy ${ }^{[2]}$, margesí o metra.

${ }^{28}$ Se refiere al Campano ilustrado. Diccionario castellano enciclopédico de Manuel González de la Rosa, París, 1891 (Alemany 1917b: VIII).

${ }^{29}$ El Diccionario completo de la lengua española de Manuel de Rodríguez Navas (Madrid, 1905).
} 
Uno de los procedimientos empleados en la crítica textual para emparentar distintas versiones de una misma obra y, así, construir su stemma estriba en detectar el error común. En lexicografía también es posible establecer la filiación con diccionarios antecesores (e incluso con contemporáneos) por medio, entre otros, de la constatación de la voz ocasional común. En el fragmento que especialmente está siendo objeto de nuestro estudio encontramos un ejemplo de este tipo. Allí se registra la voz cipizapote, con la marca fest.[ivo] y con remisión a zapote. Se trata de una creación ocasional, una deformación léxica que solo se registra en la comedia de Tirso de Molina La villana de Vallecas. Sin duda, Alemany obtuvo esta voz del DEHA, donde, además de incluirse en los mismos términos (idénticas marca y remisión), se añadía la siguiente cita tirsiana: «En conserva hay piña indiana, / y en tres o cuatro pipotes, / mameyes, CIPIZAPOTES...». ${ }^{30}$ Pero esta no es la única voz ocasional que se tomó del $D E H A$. He realizado unas calas y son muchas otras las voces que demuestran a las claras la utilización de dicho diccionario enciclopédico. De la pluma de este mismo dramaturgo áureo salieron las siguientes creaciones ocasionales registradas por primera vez en el DEHA (y lo que es más importante, con prueba palpable de su uso, una cita textual): quijotil, semicadáver, semiverdadero, seudocristo, soneta, taleguero, trotanubes, versífico, volatina o yepesino. ${ }^{31}$ Es probable que el estudioso del léxico que utilice frecuentemente el NTLLE se haya encontrado en más de una ocasión al realizar una búsqueda en dicha aplicación informática con que solo ofrecen registro de una palabra las obras de Alemany y de Pagés. ${ }^{32}$ Esta coincidencia -como fácilmente puede deducirse- se explica por el hecho de que sus diccionarios aprovecharon los materiales del $D E$ $H A$, aunque ha de decirse que cada uno lo hizo de forma muy distinta. ${ }^{33}$ Este, no obstante, no sería el único diccionario con citas textuales que se consultó para la elaboración del $D L E$; también lo fue el Diccionario enciclopédico de la lengua española (1895), de Zerolo, Toro e Isaza, o la obra del P. Mir y Noguera Rebusco de voces castizas (1907), repertorio empeñado en localizar e inventariar, cual si de tesoros se tratara, la «gran copia de vocablos» que, habiendo pasado inadvertidos por la Academia, ha permanecido «escondida en las entrañas de las obras clásicas» (Mir y Noguera 1907: v). Algunas de las voces «rescatadas» llegarían más tarde a ocupar un sitio en el repertorio académico gracias a la aportación del P. Mir, pero, antes de que tal recepción se produjera, fue el $D L E$ el primero en registrarlas, ya que el Rebusco del jesuita se aprovechó prácticamente en su totalidad. ${ }^{34}$ Algún ejemplo de lo dicho anteriormente lo constituyen las voces abrinquiñado, acalorearse, acancerado, doctrinable, felparse (felpar en el diccionario académico de 1925) o tientaparedes. No obstante, la gran mayoría de las voces del

${ }^{30}$ DEHA (1907, t. XXVI, $2^{\circ}$ apéndice). He de precisar que la remisión debería haber especificado que la voz cipizapote solo se refiere al fruto del zapote y no al árbol con el mismo nombre.

${ }^{31}$ Existen multitud de voces ocasionales que se copiaron de esta obra. De Lope de Vega es el término hociquirromo, que, según el NTLLE, solo registra Alemany, pero que indudablemente tomó del DEHA (ibid.), donde contaba con el texto siguiente: «Salió un ratón barbicano, / colilargo, HOCiQUiRromo...». Véase el apartado Diccionarios posteriores al DEHA que acusan su influencia de mi trabajo «El Diccionario enciclopédico hispano-americano de literatura, ciencias y artes (1887-1910) de Montaner y Simón: primera aproximación» (Prieto, en prensa).

${ }^{32}$ Algunas de las palabras que he citado antes pueden ser un buen ejemplo: semicadáver, semiverdadero, seudocristo, trotanubes, volatina o yepesino.

${ }^{33}$ La diferencia radica en que Aniceto de Pagés había sido en el DEHA el encargado de allegar las «autoridades de la lengua española desde su formación hasta nuestros días», y muchas de estas citas textuales, posteriormente, fueron reutilizadas para la confección del Gran diccionario de la lengua castellana (c1902-c1931).

${ }^{34}$ Digo prácticamente, porque hay voces, como concomitantemente, diablandas o fucil, que no fueron copiadas. 
Rebusco, frecuentemente por su carácter ocasional, no obtuvieron la sanción académica, pero sí la del diccionario de Alemany. Es el caso, entre otras muchas, de las voces acabriolado, ajedrezamiento, astrolabiador, baladronar, critiquez, chancillación, derramanublados, excusapecados, jactabundo, jeroglificar, longispicio, lloramicos, mediocrista, nazarear, pucheril o trujamante. ${ }^{35}$

El punto de partida de estas breves notas ha consistido en mostrar cómo Alemany asume la $14^{\mathrm{a}}$ edición del diccionario académico y, a partir de esta, de qué manera acarreó materiales lexicográficos ajenos. También ahora terminaré con el léxico de la Academia, aunque en esta ocasión, refiriéndome al primero de ellos, el denominado Diccionario de autoridades. En la aludida lista preliminar del $D L E$ existe un espacio donde se consigna lo siguiente: «REAL ACADEMIA ESPAÑOLA.-Diccionario de la Lengua Castellana (desde la 1. ${ }^{\text {a }}$ edición hasta la $14 .{ }^{\text {a }}$--Madrid, 1726-1914». Es evidente que existe una contradicción en estos datos, puesto que la primera edición no es de 1726 sino de 1780 (a no ser que se considere, por su evidente parentesco, que Autoridades es la «primera edición» de la larga serie académica). ${ }^{36}$ Unas líneas más arriba me he valido de la coincidencia de registro de voces ocasionales para emparentar el $D L E$ de Alemany con el $D E H A$, ahora me propongo hacer lo contrario, demostrar que no se utilizó el Diccionario de autoridades por medio de la ausencia de este tipo de voces en el DLE.

Los primeros académicos en su afán por inventariar todo el vocabulario de nuestra lengua (y al decir «todo» me refiero a que prestaron atención al léxico desde unos criterios muy amplios, recogiendo voces marcadas diacrónica, diatópica, diastrática y diafásicamente) ${ }^{37}$ no solo registraron palabras del sistema, comunes, o lo que es lo mismo, hechos de lengua, sino que también se permitió la entrada de la creación ocasional. Este hecho se observa claramente con un escritor (aunque no es el único) como Quevedo, citado cuantiosamente a lo largo de las 4183 páginas de Autoridades, y cuyo malabarismo verbal había de reflejarse en ellas. ${ }^{38}$ El carácter ocasional de este tipo de voces se ponía de manifiesto por medio de explicaciones en metalengua de signo tales como «es voz voluntaria», «es palabra inventada» y «es voz jocosa». Sin embargo, en la intentada segunda edición de 1770 los académicos determinaron suprimir dichos términos. El prólogo decía así: «se omiten todas las voces inventadas sin necesidad por algún autor, ya sea por jocosidad ya por otro qualquier motivo, si después no han llegado a tener uso alguno» (Academia 1770: v). ${ }^{39}$ Pues bien, índice de que no se empleó el Diccionario de autoridades para la elaboración del $D L E$ parece ser el hecho de que no se recojan voces como abernardarse, ${ }^{40}$ acertótilis, aceruelo ('espada'), acuatismo (en Autoridades con la grafía aquatismo), adonicida, agrillado («preso con grillos ['grilletes']»), aleluyado, almibarísima-

${ }^{35}$ Según el NTLLE, estas voces solo se recogen en el repertorio de Alemany (menos excusapecados, logispicio y pucheril, que también se incluyen en el Diccionario general y técnico hispanoamericano de Rodríguez Navas, Madrid, Cultura Hispanoamericana, 1918).

${ }^{36}$ No creo que se trate de esta última opción, ya que Autoridades, que tuvo una segunda edición inacabada en 1770 (letras A y B), es claramente un diccionario distinto, aunque -insisto-directamente vinculado con el nuevo formato que arranca en 1780 .

${ }^{37}$ Vid. Álvarez de Miranda (2005: 75-92).

38 Vid. Álvarez de Miranda (2004b).

${ }^{39}$ Esta supresión solo se aplicó a las letras A-C, «en cambio, el sector D-Z, cuya macroestructura se remonta directamente al Diccionario de autoridades, sigue la norma de no eliminar ninguna voz de este, incluidas, por tanto, las del grupo de las "voluntarias"》 (Seco 1991: VII).

${ }^{40}$ Me valgo de la relación de estas palabras que aparece en Garrido Moraga (1992: 277-278). 
mente (en Autoridades con -ss-), antemulas, apajado, apapagayarse, arbitrería, arbitrero, arbitriano, archidiablo, archigato, archipoeta, atarascar, autorón, avisón, ayeres, bobarria, ${ }^{41}$ bobibellaco, bodar, bonicia, borgoñarse, braquilogia (en Autoridades brachylogia) y brillesco. ${ }^{42}$ Por otro lado, no he logrado encontrar mención expresa del Diccionario de autoridades, mientras que sí se alude a distintas ediciones del diccionario «común». En la voz vagazo leemos: «voz que con las acepciones de orujo de la mesa, y residuo de la aceituna molida, figuró en las tres primeras ediciones del Diccionario de la Academia». Se refiere a las de 1780, 1783 y 1791. ¿Acaso, si se hubiera empleado Autoridades, no se habría indicado con mayor exactitud que dicha voz se registró en tal diccionario y posteriormente en las tres ediciones del usual? ${ }^{43}$

\section{CONCLUSIONES}

Con este estudio he querido mostrar de qué modo pretendió Alemany elaborar un diccionario que fuera «un registro, lo más completo posible, de la lengua hablada». Ciertamente se trataba de un proyecto muy ambicioso; sin embargo, el método emprendido para llevarlo a buen puerto no fue el adecuado. No obstante, este diccionario -justo es reconocerlo- posee otros méritos a los que también me he referido, como es el hecho de haber intentado conciliar en un solo volumen los -en muchos casos- valiosos materiales de una surtida plétora de obras lexicográficas. Haciendo mío el pensamiento de Alemany expresado en el prólogo del $D L E$, es una pena que finalmente desistieran de citar al menos los trabajos de que se sirvieron al copiar tal o cual acepción; es cierto que el tamaño de la obra hubiera crecido considerablemente, pero, así, los estudiosos del léxico habrían dispuesto de una obra aún más útil.

${ }^{41}$ Garrido Moraga escribe por error bobaria.

42 Podría objetarse, como contraargumento, que otras voces inventadas que tuvieron la misma suerte en la segunda edición de 1770 (también recogidas en el estudio de Garrido Moraga) sí llegaron a registrarse en el $D L E$, como es el caso de adanismo, afratelarse, amapolarse, apodadero, apologizar, arabio, archipobre, arremete, aruñón, batucar (Garrido Moraga escribe batugar), batuquerio, bobiculto, bobuno, bolsicalavera, broncíneo, buchar o butiro (butyro en Autoridades). Sin embargo, no parece que se tomaran estas voces de Autoridades, sino de repertorios posteriores que también las recogieron (Salvá, Domínguez, Zerolo et alii, Toro y Gómez, etc.) y de los cuales se benefició Alemany (1917b: VIII); e incluso del mismo diccionario «usual» de la Academia, que retomó en distintas ediciones varios de los términos suprimidos en 1770 (arabio, broncíneo y butiro). Si se compara, por ejemplo, la acepción de archipobre en Autoridades y en el $D L E$, puede observarse a qué me refiero. Más bien parece que se tomaron, en este caso, voz y definición del diccionario de Toro y Gómez ( $3^{\mathrm{a}}$ ed., 1906); o el verbo afratelarse, acaso copiado de Salvá, 1879 (diccionarios citados en Alemany 1917b: VIII). Por último, cabe señalar que todas las voces anteriores pasaron a registrarse en el repertorio de Alemany sin indicación alguna de su carácter de creación ocasional, pese a que pudiera (y debiera) haberse señalado esta circunstancia con las marcas fest.[ivo] o joc. [oso], consignadas en la lista de abreviaturas del $D L E$ (1917b: x).

${ }^{43}$ Asimismo, se menciona el diccionario de la Academia (también para indicar que, habiendo figurado en él un término, se suprimió en determinada edición) en artículos tales como fayanca («esta voz, que no es más que una viciosa pronunciación del catalán fallanca, la suprimió la Academia de su diccionario en la XIII edición»), japorcar, donde se señala por equivocación: «esta voz figuró en el Diccionario de la Academia hasta la edición XI, con la grafía xaporcar. En la edición XII quedó suprimida» (la voz que registró la Academia desde Autoridades hasta la 11 ${ }^{\mathrm{a}}$ edición fue xapurcar -así, sin alteración gráfica-) y japurcar (idéntica explicación a la anterior, entre corchetes, pero con los datos de registro correctos). 


\section{REFERENCIAS BIBLIOGRÁFICAS}

Alvar EzQuerra, Manuel (2002): «Diccionarios monolingües del siglo XX», en De antiguos y nuevos diccionarios del español, Madrid, Arco/Libros, pp. 342-396.

Álvarez de Miranda, Pedro (2004a): «La aspiración al "Diccionario total”: un fragmento del Diccionario general de la lengua española (c1933), de Miguel de Toro y Gisbert», en Nuevas aportaciones a la historiografia lingüistica. Actas del IV Congreso Internacional de la Sociedad Española de Historiografia Lingüistica, Madrid, Arco/Libros, I, pp. 221-236.

(2004b): «Quevedo en la lexicografía española», Edad de Oro, XXIII, pp. 389-416.

(2005): «La proeza de un diccionario con textos. Algo más sobre el Diccionario de autoridades», en Les lletres hispàniques als segles XVI, XVII i XVIII, Castelló de la Plana, Publicacions de la Universitat Jaume I, pp. 75-92.

CAstañedA, Vicente (1934): «Necrología. Don José Alemany y Bolufer», Boletín de la Real Academia de la Historia, CV, pp. 7-10 [con un apéndice de las Obras publicadas por don José Alemany y Bolufer, pp. 11-14].

Cotarelo, Emilio (1934): «Don José Alemany», Boletín de la Real Academia Española, xxI, pp. 1-6.

Diccionario enciclopédico hispano-americano de literatura, ciencias y artes (1887-1898): Barcelona, Montaner y Simón, 23 ts. [y 5 de Apéndices, 1898-1910].

Enciclopedia universal ilustrada europeo-americana (1909): Madrid, Espasa-Calpe, vol. IV [y Apéndice I, 1930].

Garrido Moraga, Antonio M. (1992): «Un episodio en la lexicografía académica del XVIII. Las supresiones en la segunda impresión del diccionario», Rilce, 8, pp. 265-285.

Martínez Camaró, Manuel (1968): Don José Alemany y Bolufer. Ensayo bio-bibliográfico, Valencia, Cosmos.

Mir y Noguera, Juan (1907): Rebusco de voces castizas, Madrid, Sáenz Jubera Hermanos.

PAGÉS DE PUIG, Aniceto de (c1902-c1931): Gran diccionario de la lengua castellana, Barcelona, Fomento comercial del libro, 5 vols. [continuado y acabado a partir del vol. IV por José Pérez Hervás].

Prieto García-SeCo, David (en prensa): «El Diccionario enciclopédico hispano-americano de literatura, ciencias y artes (1887-1910) de Montaner y Simón: primera aproximación», en Actas del VI Congreso Nacional de la Asociación de Jóvenes Investigadores de Historiografía e Historia de la Lengua Española (AJIHLE), celebrado los días 29, 30 y 31 de marzo de 2006, Universidad de Granada.

Real Academia Española (1726-1739): Diccionario de la lengua castellana [...], Madrid, Imprenta de Francisco del Hierro.

- (1770): Diccionario de la lengua castellana [...], Madrid, Joaquín Ibarra, $2^{\mathrm{a}}$ ed. [1etras A-B].

(189913): Diccionario de la lengua castellana, Madrid, Imprenta de los Sucesores de Hernando.

- (1914 $\left.{ }^{14}\right)$ : Diccionario de la lengua castellana, Madrid, Imprenta de los Srs. Hernando y Cía.

(192515): Diccionario de la lengua española, Madrid, Calpe.

(1927): Diccionario manual e ilustrado de la lengua española, Madrid, Espasa-Calpe.

(1936 $\left.{ }^{16}\right)$ : Diccionario de la lengua española, Madrid, Espasa-Calpe. 
(1970 $\left.{ }^{19}\right)$ : Diccionario de la lengua española, Madrid, Espasa-Calpe.

(2001): Nuevo Tesoro Lexicográfico de la Lengua Española, Madrid, Espasa-Calpe [2 DVD].

SECO, Manuel (1991): «Introducción», en Diccionario de la lengua castellana reducido a un tomo para su más fácil uso. Facsímil de la primera edición (1780), Madrid, Real Academia Española, pp. IIIXII.

(1994): «Menéndez Pidal y el Diccionario manual de la Academia», en Sin fronteras. Homenaje a María Josefa Canellada, Madrid, Editorial Complutense, pp. 539-547.

Zamora Vicente, Alonso (1999): Historia de la Real Academia Española, Madrid, Espasa-Calpe.

\section{APÉNDICE I}

Lista CRONOLÓGICA DE LAS PUBlicACIONES CITADAs DE José Alemany y Bolufer

(1902): Estudio elemental de gramática histórica de la lengua castellana, Madrid, Tipografía de la Revista de Archivos, Bibliotecas y Museos [2 $2^{\mathrm{a}}$ ed., 1903; $3^{\mathrm{a}}$ ed., 1911; $4^{\mathrm{a}}$ ed., 1915; $5^{\mathrm{a}}$ ed., 1919;

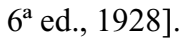

(1909): Discursos leidos ante la Real Academia Española en la recepción pública del señor D. José Alemany y Bolufer el día 14 de marzo de 1909 [título «Del orden de las palabras en la lengua indoeuropea»; contestación de D. Francisco A. Commelerán], Madrid, Tipografía de los hijos de Tello.

(1915a): La antigua versión castellana del Calila y Dimna cotejada con el original árabe de la misma, Madrid, Imprenta de los Sucesores de Hernando.

(1915b-1916a): «Voces de maragatería y de otra procedencia usadas en La Esfinge maragata, novela de Doña Concha Espina de la Serna», Boletín de la Real Academia Española, II, pp. 622-644 y III, pp. 38-63.

(1916b-1917a): «Voces extremeñas recogidas del habla vulgar de Alburquerque y su comarca por Don Aurelio Cabrera», Boletín de la Real Academia Española, III, pp. 652-666 y IV, pp. 84-106.

(1917b), dir.: Diccionario de la lengua española, Barcelona, Sopena.

(1917c y 1919): «De la derivación y composición de las palabras en la lengua castellana», Boletín de la Real Academia Española, IV, pp. 564-597, y VI, pp. 116-134.

(1920): Tratado de la formación de palabras en la lengua castellana: la derivación y la composición: estudio de los sufijos y prefijos empleados en una y otra, Madrid, Librería General de Victoriano Suárez.

(1921), dir.: La Fuente. Diccionario enciclopédico ilustrado de la lengua española, Barcelona, Sopena.

(1923), dir.: Nuevo diccionario de la lengua española, Barcelona, Sopena.

(1927): «Acerca del hipérbaton», en Estudios eruditos in memoriam de Adolfo Bonilla y San Martín (1875-1926), Madrid, Imprenta viuda e hijos de Jaime Ratés, I, pp. 609-613.

(1925a): «Acerca del origen de una m», Boletín de la Real Academia Española, XII, pp. 674-683.

(1925b): Discursos leidos ante la Real Academia de la Historia en la recepción pública del Sr. D. José Alemany y Bolufer el día 25 de enero de 1925 [título «La lengua aria. Sus dialectos y países en que se hablan. El Polo Norte, patria del pueblo ario y del género humano»; contestación de D. Adolfo Bonilla y San Martín], Madrid, Calpe. 
(1926): «Acerca de un solecismo», Boletín de la Real Academia Española, XIII, pp. 89-103.

(1927): «La naturaleza del verbo vascuence: los vascos conciben como paciente el sujeto del verbo intransitivo», Boletín de la Real Academia Española, XIV, pp. 62-81.

(1928): «Vasco no basko», Boletín de la Real Academia Española, XV, pp. 289-306.

(1929a): Gramática de la lengua achagua [del P. Alonso de Neira, comentada y expuesta por Alemany], Madrid, Imprenta Artística Sáez Hermanos.

(1929b): «Acerca de una particularidad de la lengua achagua», Investigación y Progreso, 10, pp. 88-89.

(1930): «El castellano en la Argentina según la novela de Don Carlos B. Quiroga, titulada La raza sufrida: (novela americana)», Boletín de la Real Academia Española, XVII, pp. 303-352.

(1931): «El antiguo canto de las golondrinas en la isla de Rodas y el moderno guirlando valenciano», Boletín de la Real Academia Española, XVIII, pp. 149-159.

(1932): «La expresión del plural del nombre en la declinación vasca y en otras lenguas de flexión», Boletín de la Real Academia Española, XIX, pp. 429-443.

(1933): «Más pruebas del parentesco del vasco con el caucásico y con las lenguas uralo-altaicas», Boletín de la Real Academia Española, Xx, pp. 218-242.

(1941): Gramática de la lengua griega, Madrid, Editorial Aldecoa. 
386 CIPR

CIPIPA. 1 . Fécula de la ma del Salvador, Amer. Fen is Republica del salvador, segun Toro

CIPIDAPOTE que come ren zapote.

CIPO. (dei lat. cippus) $\mathrm{m}$. Trozo de columan, pedestal moldurado o piedrs ponin en las sepulturas. Poste en pos caminos, pars indicar is direcerion o la distaneia. Hito, mojón. I p. ux.
Amer. En Colombin, trozo grande uie

clpo. (del guarani cip6). m. Amer. Bot. Enredalera con la eual oe fabriean
euerdas tan fuertes cotno las de cá Cipolino NA. adj. Dieere de una es.

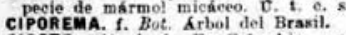

CIPOTE, adj. Anaér. En Colombia, zon zo, bobo. 0 . $t$, s. s. I Amer. Kn Gustemals, mehoncho, obeso. II Ambr. En Salvador y Honduras, chiquillo, pilluelo, muchacho $1 \mathrm{~m}$. prov.

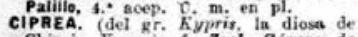

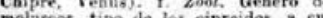

moluscos, tipo de los cipreidas, a cu-

CIPREIDOS. (de ciprea), m. Zool, Familia de moluscos prosobrazquios que tienen concha oral alary.ta, of trecha con los bordes pegados. Amer. En Méjico, el altar mayo

Por enatro altares reunidos.
CIPHES. (del lat. cypresrus; del gr. kypiristas). m. Bot. Arbol conifere siempre verde. Bu madera es rojiza Yrisdera de eate srbol.

P.1 de ramas abiertss.
CIPRESAL m. Sitio pobiado de eipreses. CIPBESINO, NA, (del lat. eypressinus;
adj. Perteneciente o parecido al ciCIPRIDE. (del gr. Kypris, Teaus), f 20\%. Cruetáceo casi microsoopico, de cipribina. bivalvo $y$ oblongo. Crustíceo ostrácodo del Oevano in dioo.

CIPRIDINENSE. adj. Geol. Aplicase a una formación o subpiso que forma parte del piso superior del terreno

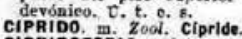

CIPRIDOFOBIA. (del gr. Kypris, Ve. nus, $y$ phobos, terror, espunto), 1. CIPPIDOLOBía, enfermedaces venereas.

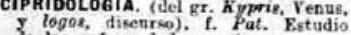
CIPRIDOPATIA. (del gr. Kyyrix, Te nus, y pathos, padeoimiento). adj nus, Y prathos, padecimiento). adj.
Pat. Nombre geuérico de las enfer medades renerens.
CIPRINA. (det lat. cuprinus, de cobre). 1 . Miner, Varie dad cuprifers de hidrocrasa.

CIPRIMIbos. (de ciprino). Im. pl. Zool. Pamilia de peces fisóstomos del gru-
po de los abdomineles, de cuerpo ovo de oblongo, comprimitio lateralmente, $y$ manndibulas debiles, sin dienter. que no existen sino en los huesos ta carpa.

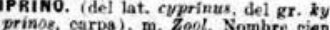
tifico de la carpa. I Nombre dado antignamente a todo pez de agua duloe.
cippino. NA. sdj. Ciprio. CIPRINO, NA. adj. ant. Cipresine CIPRINODONTE. (de ciprino y. el gr. odoús, odoptos, diente). m. 2ool, Ge.
nero de peces huesosos, del orden dio nero isosteces huesosos, del orden do los eiprinodóntidos, $y$ da nombre CIPRINODONTIOC

m. pl. Zool pos. (de eiprinodonte). m. pl. Zool. Familia de peces fiscate. racterizados por la aucencia de bar
CIRC

bas. por teber dicuter on la faringe y en las mandibulas, y por presentar CIPRINoioe. adj. Ciprinoideo. II m, pl. Zool. Ciprinidos.

IPRINOIDEO, A. (de ciprino, y el gr. al ciprino, o a que participa de ca na. turaleza. PRIA. (del lat, eyprius), ndj. Chipriota. Apl. An peri, a. t, e. CIPRIOTA. com. chipriota.

CIPRIPEDio. (del gr. Kypris, Tenus, pedion, planta del pie), m. Bot. Ge nero de plantas orquideas que viven del hemisferio boreal. y mya especie tipo es el cipripedio de los Aljes o CIPROIDEO, A. alj. Zool. Semejante a cipselídide. (de Cipselo, tirano de Co rinto). adj. pl. Hixt. Dicese de tos in dividuos de unn dinastin de prinel cipselidos. (de eipselo). m. pl. Zoot. Familia de pajaros fisirrostros, muy a golondrinas, cuso tipo CIPSELLo. (del lat, cypsêtus, veneejo) m. Zoof Nombre ejentifico del vencejo. ciptonismo. (del gr. kypto, bajar la cabeza, inclinarse), m. Género de suplicio que antiguamente be imponis n cos criminales, y que consistia malera de menor nitura que la del mombre, do cual les obligsba ta estar

CIPURA. f. Bot. Hierbs iridácen de la América tropical y subtropical.

CIQUE. m. Amer. Fn el Peru, lavadura

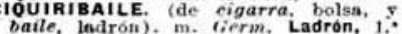
acep. ciouiricata. f. fam. Adernán o de
mostración con que se intenta lison ciouitroou halagar a alguna perzona. CIRATada de pimientos, tomates, etc. vills de in provincia de Castellon. $v$. divhn villa.

rauqui, vilis sa. adj. Natural de Civilia de la provineis de Na. lativo a dichs sills.

CIRBA. (del gr. kyrbin). f. Arqueol. Co lumna giratoria en donde se habia hecho grabar las antiguas leyes de cirbasia. (del gr, kyrbasia). f. clciriásia. f. Clrbasia.

CIRCA. $f$. Amer. Fn Chile, nceión y efee. to de eiroar.

CIRCAETO. (del gr. kirkos, halcón, y aetós, sguils). m. Zoot. Ave
la familia de las faleonidas.

Is familia de las faleonidas.
CIRCA $\mathrm{v}$. a. Min. Abrir un desealce en uno de los costados de un flion en una
und longitud de seis a siete metros, y dejarlo intsoto hasta que despues se en-

tnble la exearaoión de disfrute.
circasía NO, NA. adj. Natural de Circasia 0 . $t$. 5 . II Perteneciente 0 cirropea.

CIRCE. (del lat. Circe, nombre de la

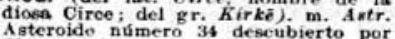
A steroide número 34

CIRCENSE. (del lat. circennnis) adj. Dicese de los juegos o espectáculos que CIRCINADO, DA. (del en el eireo.

p. p. de circinare, redondesr diepo ner en cironlo). sajj. Bot. Dispuest. circularmente o en anillo, o bien arro llado en espiral.

reo. (del lat. cirous). m. Entre los romanos, lugar destinado para algu no: espectaculos, especialmente para La carrera de carros o eabnllos. \|l Edi peotndoreg, y en medio un para los es-
CIRC:

culac. donde se ejeoutan ejeroleiog de las personas que oeupan estos saten. tos. I nat. Cerco, on ls acep. de Agra cícón. (del persn rarguin, color do oro). m. Bilicate de cirronio, mát menos transparchte, ificoloro o amari-
llento rojizo. que se nas oomo piedra Gink. circonio. (de cireán), m. Metal muy raro, pulverulento y negruzco, extraj. do del circón.

(del lat. cirruitto, inem

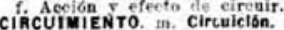

Clacuir. (det int, circutre). r. a. Ro dear, errest. pneio de terreno comprendido dentr. de un perimetro cualquiera. If Bojeo o contorno. Fis. Cosjunto del sparato productor de uns eorriente electrica,
del que ta recibe y de los hilos condue. torea que ran do uno a otro.

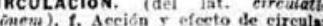
1 Quim. Operacion que consiste en ca. Ientar una substancis contenids ca uno de los matraces del raso do re. encuentro, de modo que los vapors sea en el otro matras $y$ vuelvan $\mathrm{s}$ la masa de donde salieron. I de la as. gre. Fisial. Función que consiste en is salids de is snangre urterial del ven. trieulo izouierdo del corseón para dic tribuirse por todo el cuerpo y a $x$ vuelth con las propiedades do venoes. rentriculo derecho del mismo organo. O. t. o. S. Circulante. Que circula. CIRCULLA MIENTO. $\mathrm{m}$. Circulación. CIRCULANTE. p. is de Circular. Que eircula.

(del lat. rirculario). adj. Perteneciente sl efreuto. II De figurs circular if Orien o introce, cane uns satoridad superior dirige a to o a gran parte de sus subordlinadou Carta o avizo dirigidos a direrana per. konas, para darles conocimiento de al. ClikCULAR. (del lat. circulari; de cirediss, eirculo), $x, n$, Andar o moverse ea derredor. If Ir $y$ renir. $\|$ Correr 6 pasar alguna coza de unns personas. otras. Fartir de un ecntro ordenes

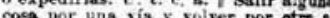
punto de partida, is Com, por otm a valores de una en otra perions me diante trueque o cambio,
CIRCULARIDAD. $\mathrm{f}$. Calidad de eireulas,

CIIRCULARMENTE. adv. m. En efroulo. latoriute), adj. Relativo a lat. circul.
latevis.

cínculo. (del lat. eircülus, dim. de circux, cerco) - m. Geom. Ares o superreneianten trito, eorro. Cerco, en iretito, dis. figurn supersticiosa on ta acep. chiecros y tikrominticos. I Antige recinto formado por menhires ptestos do treebo en trecho. I Casino, en las acceps. de sociediad de reerco $y_{\mathrm{a}}$ edi. feio destinado a la miama. If Ea al-
gunos eolegios, reunión de estudiantes gunos eolegios, reunión de estudisntes presidids por uno o más profesores, en que se defende por uno de aquellos
una tesis o conelusión contra los aruna tesis o conclusión contra los ar
gumentos de otros. II Liturg. Sentoireulo que forman los esnónigos al pie del trono del obispo euando oscia de medio pontifical, para resar jeatos determinadsy orsciones. If do re fiexion. Instramento mateasático que so compone de un circulo gradnado doa alidadas con un espejo cads uns. y sirre para medir kngulos en ess.
quier plano, repitiendolos. I horaria. 